\title{
Comentários dos Leitores dos Jornais Online: Conversa Democrática ou Discursos de Opereta Virtuais?
}

\author{
Kim Strandberg, Janne Berg \\ kistrand@abo.fi \\ Åbo Akademi University (Finland)
}

\begin{abstract}
RESUMO
As discussões online entre cidadãos são objeto de discussão académica e de diversos estudos empíricos há vários anos, tendo os estudiosos perspetivado estas discussões como potenciais lugares de deliberação dos cidadãos. Muitas vezes, contudo, os resultados empíricos não sustentam estas noções. A qualidade da discussão não é, frequentemente, adequada aos padrões das discussões deliberadas. Alguns resultados, porém, indicam que os lugares de discussão online que recorrem à utilização de facilitadores, temas fixos e à aplicação ativa de regras de discussão poderão evitar muitos dos problemas de qualidade da discussão. Este artigo apresenta, por isso, uma análise, que procura determinar se os comentários dos leitores no website de um jornal finlandês se aproximam daquilo que se designa por conversas democráticas. Ao longo de três semanas, no início de 2010 , procedemos à análise de conteúdo de 300 comentários dos leitores. Os nossos resultados indicam que, embora se encontre traços de conversas democráticas nos comentários dos leitores online, nalguns casos o oposto também é verdade.
\end{abstract}

PAlavRAS-ChaVe:

Esfera pública; comentários online de leitores; deliberação online; conversações democráticas; Finlândia

\section{INTRODUÇÃO}

O valor democrático das discussões públicas entre cidadãos é um tema que registou recentemente um impulso de crescimento na teoria democrática (Chambers, 2003). Alguns investigadores (e.g. Dryzek, 2000: 1) afirmam, inclusivamente, que, "atualmente, a essência da própria democracia consiste, sobretudo, na discussão ponderada, por oposição à votação e à agregação de interesses". Esta é, naturalmente, uma ideia que está longe de ser inovadora. As ideias de teóricos como Habermas (1989), Dahl (1989) e Barber (1984) inspiram o enfoque contemporâneo sobre deliberação. Aquilo que distingue o enfoque atual sobre deliberação do cidadão dos "turnos" anteriores, contudo, são os esforços envidados para converter a teoria em prática através de diversas formas de mini-públicos (Dryzek \& Goodin, 2006). Embora este artigo não discuta a deliberação nem os mini-públicos per se, assenta, no entanto, na teoria da deliberação, focando especificamente as conversas entre cidadãos na Internet. Considerando que as conversas democráticas exigem a presença de elementos característicos de uma sociedade face a face, ou seja grupos de dimensões razoáveis que permitam conversar e refletir (Fishkin \& Laslet, 2003), a Internet parece possuir diversas condições favoráveis às conversas democráticas. Neste sentido, Wright e Street (2007: 72) sugerem "que as características técnicas da Internet [...] conduziram à criação de um "mundo virtual" que determina as condições da democracia deliberativa". 
Porém, as condições nem sempre implicam o cumprimento das promessas. A teoria deliberativa propõe diversas condições que as conversas de cidadãos necessitam de satisfazer antes de serem consideradas conversas democráticas (ver Barber, 1984; Dahlberg, 2001; 2004; Stromer-Galley, 2007). Neste contexto, vários estudos de discussões online entre cidadãos não conseguiram obter sustentação imediata (e.g. Ferber et al., 2006; Jankowski \& Van Os, 2004; Papacharissi, 2002; Strandberg, 2005; 2008; Witschge, 2004). No entanto, os dados empíricos recolhidos a partir dos esforços envidados relativamente aos eventos de deliberação off-line (e.g. Fishkin et al., 2002) e, em certa medida, relativamente aos seus equivalentes online (e.g. Grönlund et al., 2009; Strandberg \& Grönlund, 2012) conduziram a uma observação interessante: os locais de discussão entre cidadãos concebidos como democráticos apresentam uma maior probabilidade de produzir conversas de um tipo percecionado como benéfico para a democracia (Coleman \& Moss, 2012: 6; Wright \& Street, 2007: 850).

Partindo desta observação, este artigo foca um local de discussão entre cidadãos que, salvo raras exceções (e.g. Friedman, 2011; Kohn \& Neiger, 2007; Diaz Noci et al., 2010; Ruiz et al., 2011), não tem sido alvo de muita atenção académica no contexto das deliberações de cidadãos: os comentários dos leitores sobre notícias de jornais. Neste sentido, Ruiz e colegas (Ruiz et al., 2011: 464) realçam que: "[...] é o momento para avaliar se os jornais online oferecem uma nova personificação da esfera pública, tornando-se os cafés digitais de uma Esfera Pública 2.0". Neste artigo, perguntamos em que medida as discussões de cidadãos nos comentários dos leitores constituem conversas democráticas. $\mathrm{O}$ artigo adota, assim, uma abordagem exploratória e descritiva, devendo realçar-se que não possuímos quaisquer expectativas normativas prévias de que os comentários dos leitores online deveriam satisfazer todos os critérios das conversas democráticas. A análise empírica socorre-se da análise de conteúdo, concentrando-se nos comentários da edição online de um jornal Finlandês do início de 2010 (poderá encontrar-se uma descrição mais detalhada na secção de apresentação da metodologia e dos dados).

\section{ENQUADRAMENTO}

\subsection{DISCUSSÕES DEMOCRÁTICAS}

Quais são os critérios inerentes a um processo comunicativo democraticamente benéfico? Apesar da existência de diversas variações terminológicas, é possível encontrar diversos elementos essenciais semelhantes na teorização de diversos académicos relativamente aos indicadores das conversas democráticas (e.g. Barber, 1984; Dahlberg, 2001; Jankowski \& Van Selm, 2000; Stromer-Galley, 2002). Estes deverão, se possível, ser tratados de igual modo entre os participantes na discussão (inclusão), e considerar a racionalidade, a relevância para o tema, a honestidade, a reciprocidade e a interação. Além disso, os participantes na discussão devem mostrar respeito mútuo.

A noção de esfera pública pressupõe que os cidadãos se reúnam para discutir as questões atuais (cf. Habermas, 1989), tendo-se defendido que os media modernos podem alargar esta esfera, uma vez que existem sempre dificuldades técnicas relacionadas 
com a possibilidade de permitir a co-presença física de grandes números de cidadãos. Esta perspetiva foi alvo de atenção mais intensiva do meio académico com o surgimento da Internet, que é visto por muitos investigadores como uma potencial esfera pública virtual, superando até os média tradicionais (ver, por exemplo, Papacharissi 2002; Ruiz et al. 2011; Singer, 2009).

\subsection{AS TIC E AS DISCUSSÕES DEMOCRÁTICAS}

O potencial democrático da Internet reside na sua diversidade enquanto meio, mas também na sua interatividade. Comparativamente aos média tradicionais, a Internet possui diversas vantagens, incluindo velocidade, custo de utilização reduzido, a possibilidade de comunicar facilmente utilizando multimédia e a possibilidade de publicar sem qualquer interferência dos editores (Strandberg, 2005). A Internet possui, assim, a capacidade de permitir aos cidadãos envolverem-se mais criativamente nos processos políticos, oferecendo-Ihes ferramentas de comunicação acessíveis (e.g. Barber, 1984; Dahl, 1989). Estas ferramentas incluem, atualmente, a escrita de comentários em fóruns de discussão online, blogging, comentários em notícias, partilha de conteúdos, envio de tweets e a criação ou adesão a um grupo no Facebook.

As discussões entre cidadãos online podem ser (e têm sido) vistas como versões eletrónicas das esferas públicas (Ruiz et al., 2011: 464). Além disso, podem ser realizadas facilmente, independentemente da sua localização física (Papacharissi 2002), incentivam a argumentação racional (Papacharissi, 2004), promovem a discussão política entre cidadãos (Nisbet \& Scheufele, 2004), e são, quando muito, caraterizados por uma intenção de apresentar o melhor argumento, bem como de procurar falhas nos argumentos dos outros participantes na discussão (Graham, 2009). Os resultados empíricos relativos à qualidade da discussão online são, no entanto, absolutamente inconclusivos. Embora a discussão cumpra os critérios das conversas democráticas nalguns casos (ver Stromer-Galley, 2002; Jensen, 2003; Graham, 2009), noutros casos está, muitas vezes, longe de o fazer (Wilhelm, 2000; Strandberg, 2005; 2008; Ferber et al., 2006).

\subsection{COMENTÁRIOS dOS LEITORES ÀS NOTíCIAS DE UM JORNAL ONLINE}

Os jornais, e sobretudo as suas secções públicas e as cartas ao editor, são, tradicionalmente, um fórum extremamente visível de debate e de influência da opinião pública, podendo, inclusivamente, segundo Ruiz et al. (2011: 464), considerar-se a forma mais popular de participação da audiência. Os comentários dos leitores nos artigos de jornais online representam um fórum de discussão relativamente novo entre os cidadãos, e possuem (pelo menos, teoricamente) as características necessárias para funcionarem como locais de conversas democráticas. Os comentários dos leitores online revestem-se de um formato interativo, que permite aos leitores de um jornal online exprimirem as suas perspetivas e discutirem os artigos publicados. Normalmente, os leitores podem publicar os seus comentários diretamente, como um anexo ao artigo, muitas vezes utilizando um campo dedicado a comentários por debaixo do texto. As características desses comentários dos leitores - publicação imediata, grande quantidade de espaço 
e censura mínima - oferecem aos leitores novas possibilidades de participação, sendo estas completamente distintas daquelas oferecidas pelas cartas ao editor ou pela secção do público, devido ao espaço limitado dos jornais impressos. Os comentários dos leitores permitem aos cidadãos discutir os temas em contexto, uma vez que o artigo com o qual estão relacionados determina o tema da discussão (Manosevitch \& Walker, 2009). Domingo (2008: 694), de modo idêntico, descreve os comentários dos leitores como "micro-fóruns anexos às notícias". Isto significa que os comentários dos leitores podem ser mais visíveis do que outros fóruns online independentes, e, ao mesmo tempo, promover uma discussão pública aberta.

Em paralelo com a discussão académica sobre os fóruns online em geral, a perspetiva sobre se o potencial democrático da discussão dos cidadãos poderia concretizar-se em forma de comentários dos leitores dos jornais não é, ainda, unânime. Alguns autores são perentórios em defender que os comentários dos leitores irão mudar a comunicação política positivamente (ver, por exemplo, Hecht, 2003; Manosevitch \& Walker, 2009; Schuth et al., 2007), enquanto outros estudiosos se mostram mais reticentes relativamente à fraca qualidade democrática e à falta de deliberação nos comentários dos leitores (Kohn \& Nieger, 2007; Skjerdahl, 2008; Hedman, 2009), bem como ao fraco interesse mostrado pelo público no envio de comentários (Bergström, 2008).

No respeitante aos resultados empíricos da investigação, Nagar (2009) e Hedman (2009), por exemplo, concluem que muitos editores de jornais estão claramente preocupados com o conteúdo e com a qualidade dos comentários dos leitores. Numa análise retórica dos comentários dos leitores Israelitas, Kohn e Neiger (2007) observam que os comentários refletem uma discussão violenta e agressiva, apesar de, simultaneamente, serem verbalmente refinados. A conclusão de Hecht (citado em Nagar, 2009) é que os comentários dos leitores constituem uma discussão espontânea sobre os temas atuais, diferindo dos comentários dos blogs no sentido em que adquirem maior teor de autoridade para os cidadãos. Manosevitch e Walker (2009) afirmam que os comentários dos leitores sobre os editoriais prestam especial atenção ao próprio editorial e a outros comentários, podendo vir a tornar-se uma ferramenta democrática para os cidadãos. Porém, Diaz Noci et al. (2010) apresentam resultados opostos, tendo observado que existe uma falta de respeito, perspetivas diversas e argumentos maduros. Por conseguinte, sugerem que os "comentários às notícias não estão a promover um diálogo democrático". Diaz Noci et al. também sugerem que a moderação humana antes da publicação dos comentários é o preço a pagar pelo garante do debate democrático. Num estudo transnacional de comentários online a notícias de diversos sistemas de média nos principais diários dos Estados Unidos, Reino Unido, França, Espanha e Itália, Ruiz et al. (2011) avaliam a qualidade democrática dos comentários dos leitores, tendo concluído que os comentários aos jornais online podem dividir-se em dois tipos: i) comunidades de debates e ii) comunidades homogéneas. Relativamente às primeiras, destacam que os pontos de vista opostos aos da maioria são apreciados e incentivam ao debate, enquanto, no segundo tipo, os comentários dos leitores tendem a constituir uma "reprodução coletiva das mesmas posições". Friedman (2011: 13), concentrando-se em comentários dos leitores sobre o conflito Israelo-Palestiniano em dois jornais online, chega a conclusões 
muito semelhantes, argumentando, por isso, que os comentários dos leitores online são mais bem descritos como um conjunto de "debate crítico-racional, demagogia extremista, provocação amigável, exibicionismo e apelos emocionais".

Resumindo esta secção, chamamos a atenção para o facto de ainda existir uma grande incerteza teórica e uma falta de resultados empíricos conclusivos relativamente ao potencial democrático dos comentários dos leitores online. Como Ruiz et al. (2011: 464) assinalam, "tem sido prestada pouca atenção científica à natureza destas conversas [comentários dos leitores, nota dos autores] e às suas implicações para a democracia". Assim, procuramos aprofundar a questão sobre em que medida e de que modo é que estes "micro-fóruns anexos às notícias" online (Domingo 2008: 694) cumprem os ideais das conversas democráticas deliberativas. Recorrendo à análise de um jornal publicado na Finlândia, também esperamos evidenciar um contexto comunicativo - os sistemas mediáticos democrático-corporativistas (Hallin \& Mancini, 2004) -, que foi identificado como necessitando de um estudo mais aprofundado (e.g. Ruiz et al., 2011).

\section{ABORDAGEM, DADOS E MÉTODOS}

Ao explorar em que medida e de que modo é que os comentários dos leitores online satisfazem os ideais das conversas democráticas deliberativas, procederemos a uma análise do tipo-ideal (ver Esaiasson et al., 2003: 155), através da perscrutação da medida em que os debates nos comentários dos leitores dos jornais cumprem os padrões normativos das conversas democráticas - i.e., o tipo-ideal dessas conversas. A construção deste tipo-ideal não é necessariamente uma tarefa simples, uma vez que requer a "tradução" das avaliações normativas em indicadores mensuráveis (ver Downey et al., 2012). Felizmente, já foram realizados diversos estudos sobre esta "tradução", quer por investigadores que aplicaram os princípios deliberativos na prática, através de mini-públicos (e.g. Dryzek \& Goodin, 2006), quer por investigadores que estudaram a qualidade democrática das discussões online (e.g. Dahlberg, 2001; Jankowski \& Van Selm, 2000). Embora estejamos conscientes de que foram utilizadas condições adicionais de deliberação na literatura (e.g. Trénel, 2004; Graham, 2009; Stromer-Galley, 2007), concentramo-nos em quatro áreas de interesse, numa tentativa de focar as condições mais cruciais da deliberação:

(i) a racionalidade das discussões

(ii) a relevância para o tema das discussões

(iii) a reciprocidade das discussões

(iv) o grau de cortesia e respeito nas discussões

Estas áreas podem, no entanto, ser medidas e operacionalizadas de diversas formas (e.g. Graham, 2009; Jensen, 2003; Manosevitch \& Walker, 2009; Steenberger et al., 2003). Aplicámos, no entanto, como denominador comum uma análise de conteúdo quantitativa. No sentido de procurarmos um sistema de codificação adequado ao nosso 
estudo, realizámos um teste piloto através do qual testámos os esquemas de codificação existentes com uma pequena fração dos nossos dados. Com base no teste piloto, evidenciou-se a necessidade de construir um esquema adaptado, utilizando elementos de vários esquemas'. Testámos a fiabilidade do nosso esquema utilizando a fórmula sugerida por Holsti (1969), tendo apresentado um grau altamente satisfatório de .93 de intra-fiabilidade. Embora tenhamos utilizado apenas um codificador, verificámos a fiabilidade do inter-codificador do esquema, que atingiu .83 utilizando a mesma fórmula. Este esquema adaptado mede as quatro áreas de interesse utilizando diversos indicadores diferentes ajustados a partir da literatura (Tabela 1):

\begin{tabular}{ll}
\hline \multicolumn{1}{c}{ CoNDIÇão } & \multicolumn{1}{c}{ INDICADORES/VARIÁVEIS } \\
\hline Racionalidade & $\begin{array}{l}\text { Justificação, racionalidade das afirmações, validação } \\
\text { interna, validação externa, nível de evidência }\end{array}$ \\
\hline Relevância & Relevância \\
\hline Reciprocidade & $\begin{array}{l}\text { Direção do comentário, concordância, } \\
\text { discordância, tipo de reciprocidade }\end{array}$ \\
\hline Cortesia e respeito & Tom do comentário, falta de civismo, falta de cortesia \\
\hline & Tabela 1. Áreas de enfoque e respetivos indicadores \\
Nota: Ver no anexo uma descrição das operacionalizações
\end{tabular}

$\mathrm{Na}$ análise da racionalidade das discussões, observamos vários indicadores alternativos: justificação das afirmações (Steenberger et al., 2003), raciocínio das afirmações de acordo com o tipo de argumento (Graham, 2009), validação das afirmações, bem como o tipo de prova utilizado como suporte a essas afirmações (Graham, 2009; Jensen, 2003). Estes elementos constituem formas de avaliar em que medida os intervenientes nas discussões não exprimem meramente opiniões pessoais, como também fazem um esforço para, de forma lógica e com recurso à argumentação e à utilização de referências, defender racionalmente e desenvolver as suas afirmações. A relevância, i.e. a capacidade de se manter dentro do tema, é, provavelmente, um dos aspetos mais definidos da qualidade discursiva em qualquer forma de discussão (Schneider, 1997; Jensen, 2003; Stromer-Galley, 2007; Graham, 2009). Relativamente aos comentários aos artigos noticiosos, definimos o tema como o assunto da notícia. A reciprocidade encontra-se muito próxima da essência das conversas democráticas: "[u]ma forte conversa democrática, então, implica sempre ouvir, como falar, sentir, como pensar, e agir, como refletir" (Barber, 1984:178). De modo a medir este aspeto, analisamos três indicadores nos comentários (cf. Ruiz et al., 2011): a direção da interação; a ocorrência de concordância/ discordância; e o tipo de reciprocidade. A condição final, a cortesia e o respeito, é uma condição prévia à qualidade democrática da conversa e, simultaneamente, sinal da qualidade dessas conversas (Papacharissi, 2004; ver também e.g. Graham, 2009; Jensen, 2003). Medimos esta condição recorrendo a três indicadores nos comentários: tom, grau de falta de civismo e grau de falta de cortesia.

\footnotetext{
'. Considerando os nossos objetivos, alguns dos esquemas eram demasiado aprofundados (e.g. Steenberger et al., 2003), demasiado simplistas (e.g. Manosevitch \& Walker, 2009; Jensen, 2003) ou, simplesmente, demasiado pormenorizados para analisar os comentários dos leitores (Graham, 2009).
} 
Reconhecemos, no entanto, que estas condições - e, especialmente, alguns dos seus indicadores - estão, de algum modo, inter-relacionados, sobrepondo-se até, nalguns casos. No entanto, para efeitos deste artigo, no qual pretendemos avaliar a qualidade democrática dos comentários dos leitores online (uma área por explorar), queremos manter uma mente aberta e testar várias formas de medir aspetos da qualidade democrática. Uma preocupação significativa no desempenho desta tarefa foi a forma como podemos determinar se as discussões que se desenrolam nos comentários aos artigos satisfazem as condições normativas da deliberação. Graham (2009: 53-54) também reconhece que os investigadores nunca definem explicitamente quando é que as condições normativas são realizadas. Quais são, por exemplo, os pontos de rutura entre uma discussão de fraca qualidade e uma discussão de alta qualidade? Wright (2011: 12), de igual modo, reconhece este problema e aconselha os investigadores a adotar uma abordagem mais flexível relativamente às discussões online. Segundo Wright (ibid:6-7), é frequente os investigadores criarem, simplesmente, expectativas indevidas antes de avaliarem os seus resultados empíricos, o que poderá levá-los a conclusões demasiado pessimistas. Ao efetuarmos a nossa análise do tipo-ideal, por conseguinte, também apresentamos resumidamente algumas comparações com os resultados de estudos idênticos, de modo a equilibrarmos as nossas avaliações sobre as condições normativas.

Os nossos dados provêm dos comentários dos leitores às notícias da versão online do jornal regional finlandês Vasabladet, na cidade de Vaasa. Naturalmente, o enfoque num único caso apresenta as suas desvantagens e limitações (Peters, 1998: 5-6). O jornal Vasabladet não é, por exemplo, um dos principais jornais finlandeses. Ruiz et al. (2011: 483), no entanto, destacam o valor da observação além dos principais jornais nacionais nas análises dos comentários às notícias online (cf. Downey et al., 2012: 340). Além disso, o jornal Vasabladet possui um elevado número de leitores online. O número médio de visitas únicas por semana é de 38031 (Vasabladet, 2010). A idade média dos leitores online é de 42 anos e quase dois terços dos leitores online são do sexo masculino $^{2}$. O site requer o registo (embora seja possível criar um pseudónimo) para que os leitores possam publicar comentários. $O$ website recorre à pós-moderação dos comentários dos leitores em outsourcing (ibid.).

Além disso, existem outras circunstâncias que tornam o jornal online finlandês um caso interessante. Em primeiro lugar, a Finlândia possui uma longa tradição de taxa de penetração da Internet. As notícias online encontram-se, atualmente, entre os canais multimédia utilizados mais frequentemente pelos cidadãos finlandeses em geral, incluindo as leituras sobre matérias políticas (Strandberg, 2012; Statistics Finland, 2010). A Finlândia também possui o terceiro maior grupo de leitores de jornais do mundo3.

Os dados do nosso estudo foram recolhidos entre 29 de março e 18 de abril de 2010. Durante este período, foram publicadas 305 notícias online, no website do Vasabladet. As notícias cujas discussões analisámos inscreviam-se em diversos temas, apesar

\footnotetext{
${ }^{2}$. Este perfil dos leitores online é, de facto, semelhante ao do principal diário finlandês, o Helsingin Sanomat, entre cujos leitores online também estão sobre-representadas as pessoas do sexo masculino ou com idades compreendidas entre os 25 e os 44 anos (Helsingin Sanomat, 2011).

3. Ver www.pressreference.com para consultar um resumo das estatísticas sobre os leitores dos jornais de todo o mundo.
} 
de versarem maioritariamente sobre questões sociais ou políticas (cerca de $73 \%$ de todas as notícias). O motivo que nos levou a não limitar o nosso material especificamente às notícias políticas foi a investigação, por exemplo, de Coleman e Blumler (2009) e Graham (2009), que defenderam e demonstraram que o potencial democrático dos fóruns com propósitos não políticos não deveriam ser negligenciados (cf. Wright, 2011). As 305 notícias analisadas no presente estudo obtiveram um total de 2313 comentários, com uma média de 7,58 comentários por notícia. Os comentários analisados foram selecionados aleatoriamente entre os comentários às notícias com um mínimo de 10 comentários. Este número mínimo foi determinado pela necessidade de assegurar que os comentários analisados se encontram entre as discussões mais longas, nas quais poderia efetivamente ocorrer um verdadeiro debate. O número total dos artigos com pelo menos 10 comentários ascendeu a 91 (30\% do total de 305 artigos). Com o objetivo de limitar o número de comentários a um volume possível de gerir, considerando o esquema de codificação aprofundado, selecionámos, então, aleatoriamente 300 comentários para análise, entre as 91 notícias, com um mínimo de 10 comentários anexos. O comprimento médio destes 300 comentários é de 232 caracteres (incluindo espaços), com um desvio padrão muito elevado de 206 (com o comprimento dos comentários a situar-se entre 3 caracteres e 1348 caracteres). O número de pseudónimos únicos na publicação destes comentários foi de 212, estabelecendo a média de comentários por pseudónimo em 1,4, com um desvio padrão de 2,6. O número máximo de comentários publicados recorrendo a um mesmo pseudónimo foi de nove, enquanto 37 comentários apresentavam um pseudónimo em branco. Relativamente a este aspeto, porém, não podemos deixar de realçar que os cidadãos participantes podem mudar de utilizador sempre que publicam um comentário, pelo que a média de comentários por pseudónimo deverá ser considerada apenas como uma estimativa aproximada. Note-se, também, que apenas três nomes de utilizador publicaram mais de quatro comentários cada (cf. Ruiz et al., 2011: 475-476). Quase todos os cidadãos (i.e. 96\%) que publicaram comentários recorreram à utilização de nomes de utilizador totalmente anónimos.

\section{Resultados}

Apresentamos os resultados de acordo com as nossas quatro áreas de enfoque e com os seus respetivos indicadores. Ao longo deste trabalho, também analisamos os nossos resultados à luz dos ideais deliberativos de onde decorreram. Conforme referido anteriormente, sempre que aplicável também comparamos resumidamente alguns dos nossos resultados com os de outros estudos.

\subsection{RACIONALIDADE DAS DISCUSSÕES}

De acordo com a nossa análise de 300 comentários, 83\% dos comentários (250) incluem algum tipo de afirmação por parte do cidadão que publicou o comentário. Ao analisar a racionalidade destas afirmações, portanto, começamos por observar a justificação dessas afirmações (Tabela 2). 


\begin{tabular}{clcc}
\hline \multirow{4}{*}{ Justificação } & \multicolumn{1}{c}{ N } & \% \\
\cline { 2 - 4 } & Nenhum & 40 & 16,0 \\
\cline { 2 - 4 } & Fraca & 103 & 41,2 \\
\cline { 2 - 4 } & Qualificada & 102 & 40,8 \\
\cline { 2 - 4 } & Sofisticada & 5 & 2,0 \\
\hline \multirow{2}{*}{ Total } & 250 & 100 \\
\hline
\end{tabular}

Tabela 2: Tipo de justificação nos comentários contendo pelo menos uma afirmação

A Tabela 2 mostra que, na sua maioria, as afirmações $(57,2 \%)$ não são acompanhadas por qualquer justificação, ou então apresentam uma justificação fraca. Porém, $43 \%$ das afirmações são consubstanciadas de modo satisfatório (com uma justificação qualificada ou sofisticada), o que significa que o comentário em causa inclui uma conclusão perfeitamente lógica. Considerando estes resultados em termos normativos, poderíamos concluir que a justificação dos comentários é satisfatória, mas não ideal, uma vez que grande parte dos comentários não possui uma justificação suficiente, e apenas alguns comentários possuem uma justificação sofisticada. Estes resultados são, no entanto, semelhantes aos resultados relativamente ao nível de justificação noutros contextos (Himmelroos, 2010; Lord \& Tamvaki, 2011; Spröndli, 2003). Apenas estudos de debates parlamentares na Suíça e no Reino Unido demonstraram um nível de justificação significativamente mais elevado (Steiner et al., 2004).

Ao observar o modo de raciocínio por detrás das afirmações, através do estudo do tipo de argumento que sustenta a afirmação feita, constata-se que, utilizando esta definição, $70 \%$ das afirmações (175 dos 250 comentários) feitas nos comentários apresentam um raciocínio lógico, o que equivale a $58 \%$ de todos os comentários (175 em 300). Uma vez mais, este indicador de raciocínio atinge um grau satisfatório, mas ainda possui uma margem considerável para melhoria. Os valores constantes dos nossos resultados também se encontram ligeiramente abaixo dos de outros estudos (e.g. Graham, 2009; Zhou et al., 2008), mas ao mesmo nível que o estudo de Friedman (2011). A distribuição do raciocínio lógico das reclamações de acordo com o seu tipo é apresentada na Tabela 3.

\begin{tabular}{llcc}
\hline & & N & $\%$ \\
\hline \multirow{3}{*}{ Tipo de raciocínio } & Argumento alternativo & 124 & 70,9 \\
\cline { 2 - 4 } & Prova ofensiva em contrário & 37 & 21,1 \\
\cline { 2 - 4 } & Prova defensiva em contrário & 6 & 3,4 \\
\cline { 2 - 4 } & Argumento de suporte & 8 & 4,6 \\
\hline & Total de afirmações racionais: & 175 & 100 \\
\hline
\end{tabular}

Tabela 3. Raciocínio das afirmações por tipo de argumento

Conforme ilustrado na Tabela 3, na maioria das afirmações analisadas o raciocínio lógico é articulado recorrendo a argumentos alternativos, ou seja, as afirmações são feitas sem procurar contradizer nem questionar as afirmações opositivas. Apenas $20 \%$ das afirmações incluem contra-evidência, de modo a contradizer ou a questionar as afirmações opositivas. Numa perspetiva normativa, poderemos argumentar que o recurso 
a esse tipo de prova poderia constituir o tipo de motivação mais racional. Consequentemente, o raciocínio lógico das afirmações constantes do nosso estudo está longe do ideal deliberativo do discurso racional.

$\mathrm{Na}$ Tabela 4, analisamos o indicador de racionalidade seguinte: o recurso à validação interna e externa das afirmações.

\begin{tabular}{llccc}
\hline \multicolumn{5}{c}{ VALIDAÇão INTER NA? } \\
\hline \multirow{4}{*}{$\begin{array}{l}\text { Validação } \\
\text { externa? }\end{array}$} & Não & $23 \%(69)$ & $65 \%(196)$ & $88 \%(265)$ \\
\cline { 2 - 5 } & Sim & $4 \%(12)$ & $8 \%(23)$ & $13 \%(35)$ \\
\hline Total & & $27 \%(81)$ & $73 \%(219)$ & $100 \%(300)$ \\
\hline \multicolumn{1}{c}{$\begin{array}{c}\text { Tabela 4. Validação externa e validação interna nos comentários } \\
\text { (percentagens com N correspondente entre parênteses) }\end{array}$}
\end{tabular}

$\mathrm{Na}$ Tabela 4, verificamos que a maioria das validações são validações internas, o que significa que o cidadão valida a sua afirmação com base apenas nas suas próprias perspetivas e nos seus próprios valores. A validação externa, na qual o cidadão recorre a informações de fontes externas (factos e números, por exemplo), é menos comum, sendo utilizada em apenas $12,7 \%$ dos comentários. Os comentários com recurso a validação interna e externa são raros, correspondendo a apenas $7,7 \%$ de todos os comentários. É claro, portanto, que o recurso à validação dos comentários está longe dos ideais das conversas verdadeiramente democráticas. Se o objetivo dessas discussões é constituírem-se como um "discurso crítico e racional" (Graham, 2012: 33), a maioria das validações não deveria basear-se nos próprios valores e crenças das pessoas.

Observando um último indicador de racionalidade, a sustentação das afirmações recorrendo a referências ou a provas, verifica-se, pelo menos numa perspetiva inicial (não incluída na tabela), o recurso a referências como forma de justificação de uma afirmação ou de uma opinião em 52,3\% dos comentários (157). No global, constata-se a utilização de diferentes níveis ou tipos de prova 189 vezes (um comentário poderá conter mais de um nível de prova). Porém, conforme ressalta da Tabela 5, a referência aos factos e às fontes foi utilizada como forma de substanciação de apenas 19,6\% dos comentários (37 em 300 comentários). O recurso à experiência pessoal foi utilizado nas mesmas proporções; mais frequente foi o estabelecimento de paralelos ou a utilização de algum tipo de exemplo. A utilização de paralelos ou comparações é o nível de prova mais comum, refletindo-se em 34,9\% dos comentários. Assim, de certa forma, a sustentação das afirmações recorrendo a provas é satisfatória, tendo em conta uma perspetiva do tipo-ideal. A "melhor" conclusão, neste aspeto, seria que a maioria das afirmações fosse sustentada por factos ou por fontes - o que não foi, evidentemente, o caso. Contudo, o "pior resultado possível", ou seja em que todas as afirmações seriam sustentadas meramente pela experiência pessoal enquanto prova, encontrava-se igualmente longe de um cenário real. 


\begin{tabular}{|c|c|c|c|}
\hline & & $\mathbf{N}$ & $\%$ \\
\hline \multirow{5}{*}{ Nível de evidência } & Factos ou fonte & 37 & 19,6 \\
\hline & $\begin{array}{l}\text { Paralelos ou } \\
\text { comparações }\end{array}$ & 66 & 34,9 \\
\hline & Exemplos & 50 & 26,5 \\
\hline & Experiência pessoal & 36 & 19,0 \\
\hline & Total & 189 & 100,0 \\
\hline
\end{tabular}

Nota: Um comentário poderá possuir diferentes níveis de evidência. 130 comentários possuem apenas um nível de evidência, 23 comentários possuem dois níveis, três comentários possuem três níveis e um comentário possuí os quatro níveis de evidência.

Resumindo, então, a secção sobre racionalidade, parece ser evidente que os comentários às notícias do website Vasabladet não são imediatamente racionais; curiosamente, foi possível encontrar, nas nossas variáveis, as categorias mais racionais em todos os indicadores, exceto no indicador da justificação. Uma comparação breve com outros estudos, porém, parece indicar que este resultado normativamente desencorajador não suscita uma atitude pessimista relativamente ao nosso caso finlandês.

\subsection{RELEVÂNCIA DAS DISCUSSÕES}

Os comentários aos artigos são, muitas vezes, acusados de fugir ao tema e de serem irrelevantes (e.g. Rieder, 2010). Porém, com base nos 300 comentários que analisámos, concluímos que, na sua maioria, fazem referência direta ao tema $(47,3 \%)$, ou, então, são constituídos por declarações ou clarificações, estando relacionados com o tema do artigo indiretamente $(28,7 \%)$. Os meta-comentários (comentários que refletem, sobretudo, sobre o debate) são raros (10,3\%). Os comentários irrelevantes também são pouco frequentes (13,7\%). Na sua generalidade, portanto, o critério normativo da relevância é observado, uma vez que três em cada quatro comentários se encontram relacionados com o tema. Esta conclusão também reflete as conclusões da maioria dos estudos sobre comentários de leitores online (e.g. Graham, 2009; Jensen, 2003; Diaz Noci et al., 2010; Ruiz et al., 2010), sendo, inclusivamente, mais positiva do que as conclusões dos estudos realizados por Schneider (1997) e Stromer-Galley's (2007).

\subsection{A RECIPROCIDADE DAS DISCUSSÕES}

Prosseguindo com a análise da reciprocidade das discussões, observamos, em primeiro lugar, a direcionalidade dos comentários feitos, ou seja, quem ou qual é o alvo do comentário. As nossas conclusões relativamente a este indicador mostram que o alvo das afirmações nos comentários, na sua maioria ( $\mathrm{N}=388$, uma vez que um comentário pode ser destinado a vários alvos), são as notícias (60,3\%), sendo quase todas as ocorrências restantes de afirmações direcionadas (37,6\%) orientadas para outros comentários. Por conseguinte, à luz do indicador de reciprocidade, esta conclusão é bastante satisfatória, de um ponto de vista normativo - embora, numa situação ideal, fosse de esperar uma partilha ainda mais elevada das afirmações direcionadas, tendo como objetivo outros comentários. Observando ainda mais de perto os mecanismos desta reciprocidade, analisamos o grau de concordância e discordância nas discussões (Tabela 6). 


\begin{tabular}{|c|c|c|c|c|}
\hline & & \multicolumn{2}{|c|}{ DISCORDÂNCIA } & \multirow[t]{2}{*}{ TOTAL } \\
\hline & & Não & Sim & \\
\hline \multirow{2}{*}{ Concordância } & Não & $59 \%(178)$ & $32 \%(95)$ & $91 \%(273)$ \\
\hline & Sim & $6 \%(17)$ & $3 \%(10)$ & $9 \%(27)$ \\
\hline \multicolumn{2}{|l|}{ Total } & $65 \%(195)$ & $35 \%(105)$ & $100 \%(300)$ \\
\hline
\end{tabular}

Tabela 6: Concordância e discordância

Dos 300 comentários, 59,3\% (178 comentários) não possuem quaisquer sinais de concordância ou discordância relativamente às afirmações dos outros cidadãos, o que significa que os restantes 40,7\% (122 dos 300 comentários) apresentam sinais de interação com outros comentários. A interação com outros comentários utilizando este indicador é, assim, ligeiramente superior, quando comparada com a medição da direção das afirmações aplicadas anteriormente. Porém, entre os comentários que apresentam alguma forma de interação, a discordância com afirmações de outros comentadores é o tipo predominante ( $35 \%$ de todos os comentários), contrariamente às situações de concordância ( $9 \%)$. É, no entanto, difícil avaliar se a concordância está mais próxima do ideal de conversas democráticas do que a discordância. Embora seja indubitavelmente mais desagradável do que a concordância, a discordância pode ser vista como um sinal de ambiente de discussão heterogéneo, no âmbito do qual podemos considerar uma vasta gama de perspetivas (Stromer-Galley \& Muhlberger, 2009: 175). Contudo, é de realçar que as nossas conclusões contrastam com as de uma investigação anterior sobre deliberação, na qual a concordância é mais comum do que a discordância (Stromer-Galley \& Muhlberger, 2009).

Focando, então, o nosso indicador final de reciprocidade, clarificamos o tipo de reciprocidade. Relativamente a esta medida, concluímos, surpreendentemente, que um dos participantes na discussão foi convencido pelos argumentos apresentados num comentário anterior apenas numa situação de comentário, entre todos os comentários com indicadores de reciprocidade $(\mathrm{N}=122)$. Em três quartos dos comentários $(73,8 \%)$ com interação, os comentários feitos por outros cidadãos são notados meramente sem qualquer reconhecimento do mérito das suas afirmações. Além disso, num quarto dos comentários recíprocos $(25,4 \%)$, os participantes na discussão fazem comentários negativos sobre os comentários dos outros participantes. À luz deste indicador de reciprocidade, as nossas conclusões encontram-se, portanto, bem longe do ideal das conversas verdadeiramente democráticas, uma vez que parece ser evidente que a interação com os comentários dos outros participantes na discussão são, no mínimo, bastante superficiais. A avaliar pelas conclusões de Jensen (2003), cujo estudo revelou um volume mais reduzido de reações negativas e uma maior frequência de pessoas persuadidas por terceiros, o nosso resultado também se encontra numa posição menos favorável.

Considerando a condição de reciprocidade como um todo, poderemos, então, afirmar provisoriamente que estas discussões online se encontram muito longe dos ideais normativos decorrentes da teoria deliberativa. Nenhum dos três indicadores utilizados no presente estudo revelou conclusões imediatamente encorajadoras, e as conclusões da análise do tipo de reciprocidade foram abismais, quando avaliadas relativamente aos ideais. 


\subsection{GRAU DE CORTESIA E RESPEITO NAS DISCUSSÕES}

Nesta última secção da nossa análise, refletimos sobre a última das quatro áreas de enfoque (o grau de cortesia e respeito), avaliando três indicadores: a dimensão de falta de cortesia, o grau de falta de civismo e o tom dos comentários. Relativamente aos dois primeiros indicadores, os resultados do nosso estudo são encorajadores do ponto de vista normativo: quase todos os comentários são civilizados ( $98,7 \%)$ e elaborados com cortesia (85,3\%). Esta conclusão pode, naturalmente, ser condicionada pela pós-moderação adotada pelo jornal Vasabladet, que poderá ter contribuído para uma redução desproporcionada dos comentários indelicados e rudes (cf. Ruiz et al. 2011: 482-483). Porém, as nossas conclusões parecem aproximar-se das de outros estudos (cf. Papacharissi, 2004; Ruiz et al., 2011; Diaz Noci et al., 2010).

Através da análise do último indicador da Tabela 7 - o tom dos comentários -, verificamos a existência de uma divisão equilibrada entre os comentários de natureza negativa $(42,3 \%)$ e de natureza neutra $(41,7 \%)$ ou factual $(14,0 \%)$. Por conseguinte, o tom dos comentários no website do Vasabladet é bastante satisfatório, do ponto de vista normativo, embora seja notória uma quota parte significativa de comentários negativos. Comparativamente ao estudo de Jensen (2003), os comentários dos leitores analisados no presente estudo são menos odiosos, ainda que apresentando um tom ligeiramente mais negativo e menos respeitoso.

\begin{tabular}{llcc}
\hline & & N & $\%$ \\
\hline \multirow{3}{*}{ Tom } & Ódio & 3 & 1,0 \\
\cline { 2 - 4 } & Negativo & 127 & 42,3 \\
\cline { 2 - 4 } & Neutro & 125 & 41,7 \\
\cline { 2 - 4 } & Factual & 42 & 14,0 \\
\cline { 2 - 4 } & Respeitoso & 3 & 1,0 \\
\hline Total & \multicolumn{2}{c}{300} & 100 \\
\hline \multirow{2}{*}{ Tabela 7. Tom utilizado nos comentários }
\end{tabular}

No geral, a condição normativa de cortesia e de respeito encontra-se indiscutivelmente próxima dos ideais das verdadeiras conversas democráticas. É, sobretudo, o grau elevado de negatividade encontrado na nossa análise do tom dos comentários que prejudica o ideal normativo.

\section{CONCLUSÕES}

Como referimos no início deste artigo, não possuíamos expetativas, a priori, de que as condições normativas da fala democrática deveriam concretizar-se inteiramente nos comentários aos artigos dos websites dos jornais. Pelo contrário, utilizámos estas condições normativas da nossa análise como um tipo ideal (uma espécie de medida) que nos permitisse avaliar a dimensão da qualidade democrática das discussões existentes nos comentários aos artigos online. A avaliar pelos nossos resultados, então, como é que os comentários online no website do Vasabladet se comportaram, em geral, face a esta "medida normativa"? 
Em geral, a resposta à questão acima, no âmbito do nosso estudo, é, simultaneamente, positiva e negativa. As nossas conclusões indiciam sinais positivos relativamente a um aspeto da racionalidade (justificações), bem como relativamente à relevância, cortesia e respeito dos comentários. Os resultados negativos, muito abaixo do ideal, evidenciam-se à luz da maioria dos aspetos de racionalidade, como também em termos de reciprocidade. É, portanto, evidente que, quando consideradas à luz dos ideais normativos, as nossas observações empíricas estão relativamente longe daquele que seria o cenário ideal. Porém, com base numa breve comparação a posteriori com os resultados de outros estudos, poderemos afirmar que os comentários dos leitores analisados neste estudo, regra geral, não se desviam muito mais da fala ideal do que os resultados de outros contextos comunicativos. Uma leitura bastante precisa das discussões nos comentários dos leitores online é que, por vezes, aquelas funcionam como os "cafés digitais de uma Esfera Pública 2.o" (Ruiz et al. 2011: 464); porém, o número de vezes em que tal não acontece é igual, ou mesmo superior.

Extrapolando a observação para além dos resultados empíricos, também são suscitadas algumas observações metodológicas durante o processo de realização da nossa análise que carecem de alguma atenção. Uma destas observações diz respeito à adequação da utilização de critérios decorrentes de uma teoria normativa, no contexto específico e com o tipo de dados analisados neste trabalho. Apesar de termos adaptado um esquema, com base nos processos de operacionalização dos critérios deliberativos utilizados pelos diversos estudiosos, nos mais diversos contextos, constatámos que a sua aplicação na presente análise é bastante problemática. Talvez os critérios aplicáveis às conversas democráticas sejam mais adequados a um contexto concebido mais diretamente para efeitos de deliberação, no qual é mais razoável esperar a ocorrência de conversas democráticas, como é o caso dos mini-públicos deliberativos (Dryzek \& Goodin, 2006) ou dos debates parlamentares (Steiner et al., 2004). Afinal, os jornais que permitem comentar as suas notícias online fazem-no, muitas vezes, com motivações comerciais (ver Ruiz et al., 2011: 464), e não tendo em consideração a situação do ideal de fala Habermasiana. Naturalmente, porém, a análise da fala online assente nos critérios da situação ideal de fala, seja qual for o contexto, é um bom ponto de partida, embora tenhamos que concordar, ex-ante, com a avaliação de Wright (2011: 6-7) de que este ponto de partida pode suscitar expetativas indevidas a priori, que podem conduzir a conclusões demasiado pessimistas. Seria, no entanto, de esperar que os estudos futuros procurassem adaptar os esquemas de codificação ainda mais aprofundadamente do que aquilo que nós fizemos neste estudo, com o intuito de aperfeiçoar a abordagem formulaica à análise das conversas democráticas (cf. Downey et al., 2012).

Em jeito de conclusão, procurámos explorar o porquê, então, de os comentários dos leitores não constituírem conversas democráticas. Como referimos na nossa secção de metodologia e de descrição dos dados, quase todos os cidadãos que publicaram comentários no website do Vasabladet, a exemplo do que aconteceu noutros estudos (e.g. Friedman, 2011; Ruiz et al., 2011), agiram anonimamente. $\mathrm{O}$ anonimato poderá ter 
um impacto positivo ou um impacto adverso nas discussões (e.g. Klotz, 2004; Sparks, 2001; Witschge, 2004). É perfeitamente possível, com base nos presentes resultados empíricos, que a possibilidade de "evitar assumir a responsabilidade da sua própria opinião" (Klotz, 2004: 117) afete de modo adverso as discussões nos comentários dos leitores online. Por conseguinte, incentivamos a realização de mais estudos sistemáticos, em trabalhos futuros, dedicados à comparação dos comentários de leitores anónimos e de leitores não anónimos. Por ora, juntamos a nossa contribuição a esta área de investigação, e concluímos, a exemplo de outros autores (cf. Friedman, 2011; Ruiz et al., 2011), que os comentários dos leitores online funcionam como um conjunto das duas plataformas: de conversas democráticas e de conversas de circunstância, ou operetas, virtuais.

Tradução de Rui Sousa-Silva

\section{REFERÊNCIAS}

Barber, B. (1984) Strong democracy: Participatory Politics for a New Age, Berkeley: University of California Press.

Bergström, A. (2008) 'The Reluctant Audience: Online Participation in the Swedish Journalistic Context', Westminster Papers in Communication and Culture, 5(2): 60-80.

Chambers, S. (2003) 'Deliberative Democratic Theory', Annual Review of Political Science 6: 307-326.

Coleman, S. \& Blumler J.G. (2009) The Internet and Democratic Citizenship: Theory, Practice and Policy, New York: Cambridge University Press.

Coleman, S. \& Moss, G. (2012) 'Under Construction: the Field of Online Deliberation Research', Journal of Information Technology a Poitics 9: 1-15.

Dahl, R. (1989) Demokratin och Dess Antagonister [Democracy and its Critics], New Haven: Yale University.

Dahlberg, L. (2001) 'Computer-Mediated Communication and the Public Sphere: A Critical Analysis', Journal of Computer Mediated Communication $7(1)$.

Dahlberg, L. (2004) ' Net-public Sphere Research: Beyond the "First Phase"'. Javnost - the public 11 (1): 27-44.

Diaz Noci, J., Domingo, D., Masip, P., Micó, J.L. \& Ruiz, C. (2010) 'Comments in News, Democracy Booster or Journalistic Nightmare. Assessing the Quality and Dynamics of Citizen Debates in Catalan Online Newspapers', 1Oth International Online Journalism Symposium, University of Texas, Austin

Domingo, D. (2008) 'Interactivity in the Daily Routines of Online Newsrooms: Dealing with an Uncomfortable Myth', Journal of Computer-Mediated Communication, 13: 680-704.

Downey, J., Mihelj, S., \& König, T. (2012) 'Comparing Public Spheres: Normative Models and Empirical Measurements', European Journal of Comminication 27(4): 337-353. 
Dryzek, J. (2000) Deliberative Democracy and Beyond. Liberals, Critics, Contestations, New York: Oxford University Press.

Dryzek, J. \& Goodin, R. (2006) 'Deliberative Impacts: The Macro-Political Uptake of Mini-Publics', PoliticsQ Society 34(2): 219-224.

Esaiasson, P., Gilljam, M., Oscarsson, H. \& Wängnerud, L. (2003) Metodpraktikan. Konsten att studera samhälle, individ och marknad, Stockholm: Norstedts förlag.

Ferber, P., Foltz, F. \& Pugliese, R. (2006) 'Community Networks and Public Participation: A Forum for Civic Engagement or a Platform for Ranting Irate Malcontents?', Bulletin of Science, Technology Q Society, 26( 5): 388-397.

Fishkin J.. Luskin R. \& Jowell R. (2002) 'Considered Opinions: Deliberative Polling in Britain', British Journal of Political Science, 32: 455-87.

Fishkin, J. \& Laslett, P. (eds) (2003). Debating Deliberative Democracy, Oxford: Blackwell

Friedman, E. (2011) 'Talking back in the Israeli-Palestinian conflict: rational dialogue or emotional shouting match?’, Conflict a'Communication Online, 10(2).

Graham T. (2012) 'Beyond "Political” Communicative Spaces: Talking Politics on the Wife Swap Discussion Forum', Journal of Information Technology Q Politics, 9(1): 31-45

Graham, T. (2009) What's Wife Swap Got to do With it?, Amsterdam: Amsterdam University Press.

Grönlund, K., Strandberg, K., \& Himmelroos, S. (2009) 'The Challenge of Deliberative Democracy Online A Comparison of Face-to-Face and Virtual Experiments in Citizen Deliberation', Information Polity 14: 187-201.

Habermas, J. (1989). The Structural Transformation of the Public Sphere: An Inquiry Into a Category of Bourgeois Society, Cambridge: Polity Press.

Hallin, D. \& Mancini, P. (eds.) (2004) Comparing Media Systems: Three Models of Media and Politics, New York: Cambridge University Press.

Hecht, Y. (2003) 'The Struggle for Hegemony in Digital Content - The Case of the Talk-Back', Israel Internet Association Magazine: November.

Hedman, U. (2009) 'Läsarmedverkan: Lönande Logiskt Lockbete. Nättidningarnas Användarskapade Innehåll ur ett Redaktionellt Ledningsperspektiv', Arbetsrapport nr. 56. Göteborgs universitet: Institutionen för journalistik och masskommunikation.

Helsingin Sanomat (2011) 'HS.fi-profiili', report: Helsingin Sanomat.

Himmelroos, S. (2010). Medborgare i Demokratiska Samtal - Ett Verktyg för Analys av Deliberativa Processer, Licentiate thesis, Åbo: Åbo Akademi.

Holsti, O. (1969) Content analysis for the social sciences and humanities, Reading, MA.: Adolson-Wesley.

Jankowski, N. \& Van Selm, M. (2000) 'The Promise and Practice of Public Debate in Cyberspace', in Hacker, K. \& Van Dijk, J. (eds.), Digital Democracy: Issues of Theory and Practice, pp. 149-165. London: Sage.

Jankowski, N. \& Van Os, R. (2004) 'Internet-Based Political Discourse: A Case Study of Electronic Democracy in Hoogeveen', in Shane, P. (ed.), Democracy Online: The Prospects for Political Renewal Through the Internet, pp. 181-194. New York: Routledge. 
Jensen, J. (2003) 'Public Spheres on the Internet: Anarchic or Government-Sponsored - A Comparison', Scandinavian Political Studies, 26(4).

Klotz, R. (2004) The politics of internet communication, Maryland: Rowman \& Littlefield.

Kohn, A. \& Neiger, M. (2007) 'To Talk and To Talkback: Analyzing the Rhetoric of Talkbacks in Online Journalism', in Shwartz-Altshuler, T. (ed.), Online Newspapers in Israel, pp. 321-350, Israel: The Israel Democracy Institute and Ben-Gurion University of the Negev, Burda 23 Center for Innovative Communications.

Lord, C. \& Tamvaki, D. (2011) 'The Politics of Justification? Applying the Discourse Quality Index to the Study of the European Parliament', RECON Online Working Paper (3).

Manosevitch, E. \& Walker, D. (2009) 'Reader Comments to Online Opinion Journalism: A Space of Public Deliberation', article presented on The International Symposium on Online Journalism, Austin, TX: April 17-18, 2009.

Nagar, N. (2009) 'The Loud Public: Users' Comments and the Online News Media', unpublished manuscript.

Nisbet, M. \& Scheufele, D. (2004) 'Political Talk as a Catalyst for Online Citizenship',..Journalism Q Mass Communication Quarterly, 81: 877-895.

Papacharissi, Z. (2002) 'The Virtual Sphere. The Internet as a Public Sphere', New Media Q Society, 4(1): 9-27.

Papacharissi, Z. (2004) 'Democracy Online: Civility, Politeness, and the Democratic Potential of Online Political Discussion Groups', New Media Q Society 6(2): 259-283.

Peters, G. (1998) Comparative Politics Theory and Methods, New York: New York University Press.

Rieder, R. (2010) 'No Comment: It's time for news sites to stop allowing anonymous online comments', American Journalism Review June/July 2010. <http://ajr.org/article.asp?id=4878> Retrieved Mars 1, 2012

Ruiz C., Domingo D., Mico, J., Diaz Noci, J., Meso, K. \& Masip, P. (2011) 'Public sphere 2.o? The Democratic Qualities of Citizen Debates in Online Newspapers', International Journal of Press/Politics, 16 (4): 463-487.

Schneider, S. (1997) Expanding the Public Sphere through Computer-Mediated Communication: Political Discussion about Abortion in a Usenet Newsgroup, MIT, Cambridge, MA.

Schuth, A., Marx, M. \& de Rijke, M. (2007) Extracting the Discussion Structure in Comments on News-Articles, University of Amsterdam.

Singer, J. (2009) 'Separate Spaces: Discourse About the 2007 Scottish Elections on a National Newspaper Web Site', The International Journal of Press/Politics 14: 477-496.

Skjerdahl, T. (2008) 'New Media and New Editorial Challenges: Lessons from Norway', Information sciences (Informacijos mokslai), 47: 66-77.

Sparks, C. (2001) 'The Internet and the Global Public Sphere', in Bennett, L. \& Entman, R. (eds.) Mediated politics. Communication in the future of democracy, New York: Cambridge University Press.

Spröndli, M. (2003) 'Discourse Quality and Political Decisions: An Empirical Analysis of Debates in the German Conference Committee', report, Social Science Reserarch Center Berlin. 
Statistics Finland (2010) 'Sosiaalinen Media: Verkkomedian ja Yhteisöpalvelujen Käyttö' , report, available at <http://www.stat.fi/til/sutiv/2010/sutivi_2010_2010-10-26_kat_003_fi.html (accessed May 2012)

Steenberger, M., Bächtiger, A., Spröndli, M. \& Steiner, J. (2003) 'Measuring Political Deliberation: a Discourse Quality Index', Comparative European Politics, 1: 21-48.

Steiner, J., Bächtiger, A., Spröndli, M. \& Steenbergen, M. (2004) Deliberative Politics in Action, Cambridge: Cambridge University Press.

Strandberg, K. \& Grönlund, K. (2012) 'On-line Deliberation and its Outcome - Evidence from the Virtual Polity Experiment', Journal of Information Technology Q Politics 9(2): 167-184.

Strandberg, K. (2005) “ "Town Hall” meetings for the Masses or "Social Clubs" for the Motivated? - A Study of Citizens' Discussions on the Internet', World Political Science Review 1 (1): 1-19.

Strandberg, K. (2008) 'Public Deliberation Goes On-line? An Analysis of Citizens' Political Discussions on the Internet Prior to the Finnish Parliamentary Elections in 2007', Javnost - The Public, 15(1): 71-90.

Strandberg, K. (2012) 'Sosiaalisen Median Vallankumous? Ehdokkaat, Valitsijat ja Sosiaalinen Media Vuoden 2011 Eduskuntavaaleissa', in Borg, S. (ed.) Muutosvaalit, Helsinki: Ministry of Justice.

Stromer-Galley, J. \& Muhlberger, P. (2009) 'Agreement and Disagreement in Group Deliberation: Effects on Deliberation Satisfaction, Future Engagement, and Decision Legitimacy', Political Communication 26(2): 173-192.

Stromer-Galley, J. (2002) 'New Voices in the Public Sphere: A Comparative Analysis of linterpersonal and Online Political Talk', Javnost - The Public 9(2): 23-42.

Stromer-Galley, J. (2007) 'Measuring Deliberation's Content: A Coding Scheme', Journal of Public Deliberation, $3(1)$.

Trénel, M. (2004). 'Measuring the Deliberativeness of Online Discussions. Coding Scheme 2.4', report, Berlin: Social Science Research Centrex.

Vasabladet (2010) 'Webbundersökningen', internal statistics report. Kärkimedia.

Wilhelm, A. (2000) Democracy in the Digital Age: Challenges to Political Life in Cyberspace, New York: Routledge

Witschge, T. (2004) 'Online Deliberation: Possibilities of the Internet for Deliberative Democracy', in Shane, P. (ed.), Democracy Online: The Prospects for Political Renewal through the Internet, pp. 109-122. New York, NY: Routledge.

Wright, S. \& Street, J. (2007) 'Democracy, Deliberation and Design: the Case of Online Discussion Forums', New Media Q Society, 9(5): 849-869.

Wright, S. (2011) 'Politics as Usual? Revolution, Normalization and a new Agenda for Online Deliberation', New Media Society:Advance online publication. doi:10.1177/1461444811410679

Zhou, X., Chan, Y. \& Peng, Z. (2008) 'Deliberativeness of Online Political Discussion', Journalism Studies, 9(5): 759-770. 


\title{
ANEXo: Esquema de CODIFICAÇÃo ADAPTADO
}

\section{CRITÉRIOS: RACIONALIDADE}

\author{
Variável: justificação
}

(o) Sem justificação: um falante diz apenas que se deveria ou não deveria fazer $X$, mas não indica o motivo.

(1) Justificação fraca: neste caso, é apontado o motivo $Y$ para o facto de se dever ou não fazer $X$, mas não se estabelece qualquer relação entre $X$ e $Y$; a inferência encontra-se incompleta. Este é, também, o código utilizado quando uma conclusão é sustentada meramente por ilustrações.

(2) Justificação qualificada: estabelece-se uma relação com o motivo pelo qual se espera que $X$ contribua para ou prejudique $Y$.

(3) Justificação sofisticada: neste caso, são apresentadas pelo menos duas justificações completas, seja duas justificações completas para a mesma questão, seja justificações completas para duas questões diferentes.

\section{Variável: afirmações racionais. Sim/Não}

Nota: A distinção entre os quatro tipos de argumentos abaixo reside na sua relação partilhada com os restantes.

Contraposição: Uma mensagem que fornece uma afirmação racional, e onde se propõe uma afirmação alternativa que não contradiz nem questiona diretamente uma afirmação ou um argumento antagónico, ou seja, um argumento inicial, afirmação inicial, declaração, declaração não racional, contraposição ou contra-afirmação. Sim/Não

Contestação: Uma mensagem que fornece uma afirmação racional que contradiz ou questiona diretamente um argumento inicial, afirmação inicial, contraposição, contra-afirmação, refutação não racional, refutação, declaração não racional ou declaração. Contrariamente à contraposição, uma contestação contradiz ou questiona diretamente uma afirmação ou argumento opositivo. Sim/Não

Refutação: Uma mensagem que apresenta uma afirmação racional, e que defende diretamente um argumento inicial, afirmação inicial, contraposição, contra-afirmação, declaração não racional ou declaração contra uma contestação ou contestação não racional correspondente. Uma refutação representa uma resposta defensiva contra uma contestação. Sim/Não

Declaração: Uma mensagem que presta apoio racional direto ou indireto a favor da afirmação de um outro participante é codificada como uma declaração. Sim/Não

\section{Variável: Validação externa}

o participante na discussão utiliza informações de fontes externas e segue um argumento com base em factos e números, etc. Sim/Não 


\section{Variável: Validação interna}

o participante na discussão constrói o seu argumento com base nos seus pontos de vista, nas suas posições e nos seus valores, mas estes são explicitados na argumentação. Sim/Não

\section{Variável: nível de evidência}

Factos ou fontes

$$
\operatorname{Sim} / \text { Não }
$$

Paralelos ou comparações

Histórias (baseadas em situações reais, mas hipotéticas, e não experiências pessoais) $\operatorname{Sim} /$ Não

Experiência pessoal Sim/Não

\section{CRItÉrios: RelevÂncia}

\section{Variável: relevância}
1. Diretamente sobre o tema - claramente referente ao tema do artigo
2. Indiretamente sobre o tema - clarificações, afirmações que são relevantes para o tema
3. Reflexão sobre a discussão
4. Irrelevante

\section{CRITÉRIOS: RECIPROCIDADE}

Variável: direção do comentário - a quem se destina o comentário?

\begin{tabular}{lc} 
Jornal & \multicolumn{1}{c}{$\operatorname{Sim} /$ Não } \\
Jornalismo & \multicolumn{1}{c}{$\operatorname{Sim} /$ Não } \\
Notícias & Sim/Não \\
Outros comentários & $\operatorname{Sim} /$ Não
\end{tabular}

\section{Variável: Concordância}

Um sinal de apoio a algo dito por um falante anterior, incluindo o moderador. Trata-se de afirmações como "Eu sei", "Concordo", "É verdade", "Eu também acho que a seleção regional é uma boa ideia" (no seguimento da afirmação de um falante anterior, constatando que a seleção regional era uma boa ideia) ou "Eu acho que o acompanhamento pessoal é uma boa/extraordinária/fantástica/excelente ideia", depois de um falante anterior ter sugerido mais acompanhamento pessoal por parte das escolas. A declaração de concordância é a afirmação da opinião. Sim/Não 


\section{Variável: Discordância}

Uma declaração que marca a oposição a algo dito por um falante anterior, incluindo o moderador. A discordância ocorre das seguintes formas:

"Em parte, discordo", "Não tenho bem a certeza de que" e "Não é verdade".

Frequentemente, uma discordância é marcada por "bem" antes de esclarecer aquilo de que se discordo.

As afirmações deste tipo podem começar com "Concordo, mas ..." ou possuir uma declaração adversativa "mas", que funciona como uma refutação de uma afirmação de um falante anterior.

Pode repetir parte das ideias de um falante anterior, ao mesmo tempo que altera alguns aspetos de pormenor para assinalar a discordância $(A=$ "O encerramento das escolas terá como consequência layoffs, o que irá enfurecer as pessoas." B = "O encerramento das escolas terá como consequência layoffs, mas é assim que tem que ser."). $\operatorname{Sim} /$ Não

Variável: Tipo de reciprocidade (se todos os elementos abaixo forem classi-

ficados como "não", não existe qualquer reciprocidade no comentário)

Persuasão - existem sinais explícitos de que um participante se sente persuadido pela argumentação de outro participante ou pela publicação em geral. Sim/Não

Evolução - um participante faz uma reflexão acerca de outra publicação e responde ao participante com novos argumentos ou com novas informações, ou tenta criar uma síntese de outros argumentos. $\operatorname{Sim} /$ Não

Radicalização - um participante reage de forma explicitamente negativa a outra publicação, toma o assunto como pessoal ou torna-se ofensivo e/ou radicaliza o seu ponto de vista anterior. Sim/Não

\section{CRitérios: Grau de cortesia e Respeito nas discussões}

\section{Variável: Tom do comentário}

Que tipo de tom é utilizado no comentário?

o. Ódio

1. Negativo

2. Neutro

3. Factual

4. Respeitoso

\section{Variável: Falta de civismo Sim/Não}

O índice de civismo, composto por três itens, é constituído pelas três questões seguintes. As opções de resposta a estas questões são sim (S) ou não (N). Se a resposta a pelo menos uma das questões acima for afirmativa, a mensagem é assinalada como falta de civismo. 
(1) O participante na discussão verbaliza uma ameaça à democracia (por exemplo, propõe derrubar à força um governo democrático)?

(2) O participante na discussão atribui estereótipos (por exemplo, associa uma pessoa a um grupo, recorrendo a rótulos, sejam eles mais suaves ("liberal"), ou mais ofensivos ("maricas"))?

(3) O participante na discussão ameaça os direitos das outras pessoas (como a liberdade pessoal, a liberdade de expressão)?

\section{Variável: Falta de cortesia Sim/Não}

A cortesia é avaliada de forma semelhante ao civismo, tendo-se utilizado um índice. Se uma mensagem incluir pelo menos um caso de falta de cortesia, é assinalada como sendo indelicada. Existindo ocorrências de insultos (como anormal, traidor, chanfrado), suspeição (como negligente, irracional, não-Americano), sinónimos de mentiroso (como falso, farsa), hipérbole (como ultrajante, abominável), palavras indicativas de falta de cooperação, termos pejorativos ou ordinarices, então a mensagem é classificada como sendo indelicada. Do mesmo modo, a ocorrência de outros casos de falta de cortesia relacionadas com sarcasmo, utilização de texto totalmente em maiúsculas (frequentemente utilizado online para assinalar gritos), ou outros tipos de comportamento indelicado menos óbvios implica a sua classificação como outro. 